of mouse liver regenerating after partial hepatectomy or carbon-tetrachloride poisoning, using 8-hydroxyquinoline glucuronide as substrate. In contrast to the mitochondrial site in normal liver, $\beta$-glucuronidase activity as detected by this method now appears to correspond in situation to the nucleus (Fig. 2). This did not result from aggregation of the mitochondria, which were seen to be normally situated in sequent sections stained with Iron Hæmatoxylin after fixation in Regaud's fluid. On the other hand, Feulgen staining in regenerating liver gave a similar picture to that obtained by the glucuronidase method. Normal liver sections stained by the Feulgen method did not in any way resemble those obtained histochemically.

It should be noted that biochemical methods suggest that mitochondrial glucuronidase activity remains at the normal level in regenerating liver, whereas the fraction of the enzyme which is soluble in acidified water homogenates rises in activity ${ }^{4}$. The apparent discrepancies between the results obtained by the two techniques will form the starting point for further investigation.

One of us (J. G. C.) is in receipt of a full-time grant from the British Empire Cancer Campaign.

Poultry Research Centre, J. G. CAMPBELI King's Buildings,

Edinburgh 9.

Rowett Research Institute,

G. A. Levvy

Bucksburn, Aberdeenshire. July 7.

'Friedenwald, J. S., and Becker, B., J. Cell. Comp. Physiol., 31, 303 (1948).

${ }^{2}$ Campbell, J. G., Brit. J. Exp. Path., 30, 548 (1949).

${ }^{3}$ Levvy, G. A., Kerr, L. M. H., and Campbell, J. G., Biochem. J., 42, 462 (1948).

4 Kerr, I. M. H., Levvy, G. A., and Walker, P. G., Biochem. J., 47, 403, xxx (1950).

\section{Inhibition of Chymotrypsin by Diethyl p-Nitrophenyl Phosphate}

Снymotrypsin displays both esterase and proteolytic activity, and it has recently been shown ${ }^{1}$ that this enzyme is inhibited by diisopropyl fluorophosphonate and that loss of esterase activity is paralleled by loss of proteolytic activity. Diethyl $p$-nitrophenyl phosphate $(E .600)$ resembles diisopropyl fluorophosphonate in being a very powerful anticholinesterase. We have found that it will also inhibit chymotrypsin, and have been studying the system chymotrypsin-diethyl $p$-nitrophenyl phosphate as a convenient model for other esterase systems, since the physical data for this enzyme (purity, molecular weight, etc.) are among the more accurately known.

Our sample of crystalline chymotrypsin was found to be 50.2 per cent pure (the remainder being magnesium sulphate) by using Anson's method of estimation $^{2}$ (digestion with denatured hæmoglobin in phosphate buffer, $p \mathrm{H} 7 \cdot 7$ at $25^{\circ}$, and using Northrop's value of $(0.038 \text { T.U. })_{\text {mgm.P.N. for the activity of }}^{\text {Hb }}$ pure enzyme). The inhibitory effect of diethyl $p$ nitrophenyl phosphate was followed by incubating the enzyme in buffer $p H 7.7$ at $25^{\circ}$ for $18 \mathrm{hr}$. and the proteolytic activity estimated as above. A concentration of diethyl $p$-nitrophenyl phosphate of $8 \times 10^{-5} \mathrm{M}$ gave 50 per cent inhibition of $0 \cdot 1$ per cent chymotrypsin under the above conditions. A yellow colour

developed in the solutions during incubation and the absorption spectrum corresponded to that of nitrophenol. Measurement of the absorption at $400 \mathrm{~m} \mu$ using a Beckmann photo-electric absorptiometer was a convenient method for the assay of nitrophenol. It was found that more nitrophenol was liberated in the presence of the enzyme than in its absence; the results of a typical experiment were as follow.

Solution

(a) Chymotrypsin $(0.993 \mathrm{mgm} / \mathrm{ml})+.E .600$ $\left(10^{-3} M\right)$ in phosphate buffer $p$ H $7 \cdot 7$ incubated for 18 hr. at 25

(b) Control, as above, but omitting chymotrypsin Extra nitrophenol produced in $(a)$ Inhibition of enzyme after $18 \mathrm{hr}$. $=100$ per cent.

Using a value of $27,000 \pm 1,000$ for the molecular weight of the chymotrypsin (see Jansen et $a l_{.}{ }^{2}$ ) and assuming an equation:

Chymotrypsin $+(\mathrm{EtO})_{8} \mathrm{PO} . \mathrm{OC}_{8} \mathrm{H}_{8} \mathrm{NO}_{\mathrm{s}}=$

(Inhibited chymotrypsin-PO(OEt) $\left.)_{3}\right)+\mathrm{HO}_{2} \mathrm{C}_{8} \mathrm{H}_{4} \mathrm{NO}_{4}$

the theoretical concentration of nitrophenol expected would be $(1.81+0.07) \times 10^{-5} M$.

Simultaneous determinations were made of the nitrophenol liberated and the percentage inhibition of the enzyme during $\mathbf{1 8} \mathrm{hr}$, and the results are shown in the accompanying graph. The two curves are essentially coincident, and a linear relationship is found on plotting nitrophenol liberated against percentage inhibition. These results suggest that there may be only one 'active centre' in the chymotrypsin molecule, in agreement with the findings of Jansen et al. ${ }^{3}$, who found that chymotrypsin inhibited with diisopropyl fluorophosphonate containing phosphorus-32 had $1 \cdot 1$ atoms of marked phosphorus to 1 molecule of enzyme after recrystallization.

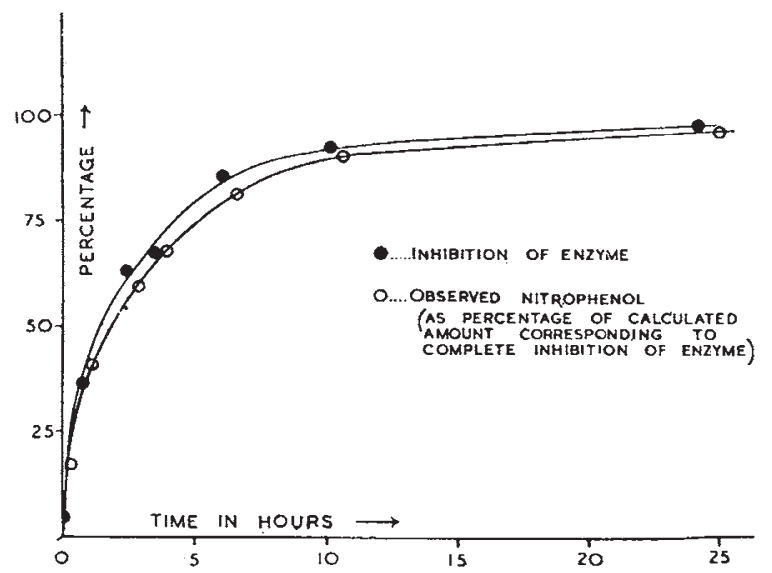

As a working hypothesis of the mechanism of esterase activity, we think it probable that one molecule of substrate reacts at the active centre of the enzyme and hydrolysis occurs. Normally, both the alcohol and acid moieties then leave the active centre and the cycle is repeated; but if certain inhibitory substrates are used, such as diethyl $p$-nitrophenyl phosphate or diisopropyl fluorophosphonate, the acid portion of the substrate (that is, $-\mathrm{PO}(\mathrm{O} R)_{2}$ ) remains attached after hydrolysis and blocks the active centre, while the other portion (for example, nitrophenol or hydrogen fluoride ?) is liberated. Further work on the kinetics of the reaction and the use of radioactive inhibitors is in progress. 
Our thanks are due to Armour and Co., of Chicago, for a gift of crystalline chymotrypsin, and to the Agricultural Research Council for financial support. B. S. HaRTLEY

Department of Biochemistry,

$$
\text { B. A. Kilby }
$$

School of Medicine,

Leeds 2. July 5.

' Jansen, E. F., Nutting, M. D. F., Jang, R., and Balls, A. K., J. Biol. Chem., 179,189 (1949).

${ }^{2}$ Anson, M. L., J. Gen. Physiol., 22, 207 (1938). Jansen, E. F., Nutting, M. D. F., and Balls, A. K., J. Biol. Chem.,
179, 201 (1949).

\section{Beta- and Gamma-Globulin Tetanus Antitoxin of the Hyperimmune Horse}

PAST work has indicated that fractionation of diphtheria antitoxic horse serum yields fractions of which the dilution ratio, and hence the firmness of combination, may show considerable variations. There was a definite correlation between the in vitro/in vivo ratio and the dilution ratio ${ }^{1}$. Kekwick and Record ${ }^{2}$ examined electrophoretically pure gamma- and betaglobulin from hyperimmune horse sera, and found that both fractions had antitoxic activity and that they differed in their $L+/ L_{f}$ ratios and in their speed of flocculation. It was of interest to investigate whether this was a general phenomenon, or one confined to the diphtheria toxin-antitoxin system, by studying the relation between tetanus toxin and horse tetanus antitoxic sera.

Qualitative differences between tetanus antitoxic sera have been observed by Hartley (quoted in ref. 3) and Petrie. Dilution tests ${ }^{5}$ on two sera and two fractions from one of them indicated a similarity to the diphtheria toxin-antitoxin system, and Kekwick ${ }^{6}$ demonstrated that both gamma- and beta-globulin were antitoxic.

Gamma- and beta-globulin were obtained by fractionation with sodium sulphate followed by electrophoretic separation ${ }^{2,8}$ from sera of horses hyperimmunized intramuscularly with tetanus toxoid. Flocculation always gave multiple zones. The flocculation zone due to tetanus toxin was determined by preparing floccules near each of the indicating mixtures, using proportions providing excess of toxin or antitoxin. The floccules were washed and then added to a suitably diluted solution of antitoxin. Toxinantitoxin floccules absorb considerable quantities of antitoxin and may be distinguished in this way from floccules derived from flocculation zones involving other antigens ${ }^{7}$. $L_{f}$ and $K_{f}$ were determined at $49^{\circ} \mathrm{C}$. in phosphate buffer, $I=0 \cdot 2, p \mathrm{H} 8$.

The extent to which toxin-antitoxin dissociates on dilution was tested in two ways : (1) the amount of an antitoxin was found that would neutralize an

\begin{tabular}{|c|c|c|c|c|c|}
\hline Antitoxin & $K_{f}$ & \multicolumn{2}{|c|}{$\frac{L+\text { units perml. }}{L f}$} & $\frac{M}{\bar{G}} \times 100$ & $\frac{L+/ 250}{L+/ 5} \times 500$ \\
\hline \multirow{4}{*}{$\begin{array}{l}\text { 'Keeble' } \\
\text { serum } \\
\text { 'Keeble' } \\
\text { gamma- } \\
\text { globulin } \\
\text { 'Keeble' } \\
\text { beta- } \\
\text { globulin }\end{array}$} & & $a$ & $b$ & & \\
\hline & $145^{\prime}(1)$ & 1.5 & $2 \cdot 2$ & 87 & 68 \\
\hline & $69^{\prime}(2)$ & $2 \cdot 6$ & $4 \cdot 4$ & 60 & 55 \\
\hline & $165^{\prime}(1)$ & $1 \cdot 2$ & $1 \cdot 3$ & 106 & 95 \\
\hline
\end{tabular}

(1) 6 units $/ \mathrm{ml}$. of flocculation mixture.

(2) $4 \cdot 2$ unitshnl. of flocculation mixture.

(b) Determined from $L+/ 250$ measurements.
$L+/ 5$ dose of toxin and was compared with the amount required to neutralize an $L+/ 250$ dose of toxin $^{5}$; (2) the amounts required to neutralize the test dose of toxin in the mouse and in the guinea pig were compared. ( $M / G$ is ratio of $L+$ units per ml. in the two cases. $\left.{ }^{4}\right)$

It may be concluded that, in flocculating, tetanustoxin-antitoxin systems resemble diphtheria toxinantitoxin mixtures. The gamma-globulin combines more avidly than the beta-globulin with the toxin; it dissociates less on dilution.

This work will be presented in detail elsewhere. Our thanks are due to Dr. R. A. Kekwick for suggesting this investigation and for his encouragement.

B. CINADER

B. WeITZ

Lister Institute of Preventive Medicine, London, S.W.1. July 4.

${ }^{1}$ Barr, M., and Glenny, A. T., J. Path. Bact., 34, 539 (1931) ; Brit. J. Exp. Path., 12, 337 (1931). Glenny, A. T.., and Barr, M., J. Path. Bact., 35, 91 (1932).

${ }^{2}$ Kekwick, R. A., and Record, B. R., Brit. J. Exp. Path., 22, 29 (1941). ${ }^{3}$ Hartley, P. (Llewellyn-Smith, M., 1938), Bull. Health Org. L. of N., 7. 739 .

4 Petrie, G. F.. Bull. Health Org. L. of N., 10, 113 (1942-44).

${ }^{\circ}$ Glenny, A. T., Barr, M., Ross, H. E., and Stevens, M. F., J. Path. Bact., 35 (2), 495 (1932).

${ }^{6}$ Kekwick, R. A., Chem. and Indust., 60, 486 (1941).

'Moloney, P. J., and Hennessy, J. N., J. Immunol., 48, 345 (1944).

\section{Connective Tissue Permeability and the Mode of Action of Hyaluronidase}

THE following observations would seem to throw fresh light upon the question of the mode of action of hyaluronidase on connective tissue permeability.

A sheet of fresh fascia from the flank of a mouse was fixed as an occluding membrane across the end of a glass tube of some $0.5 \mathrm{~cm}$. internal diameter : rubber rings were found to be the best method of sealing the membrane to the tube. Particular care was taken not to damage the membrane during dissection or to stretch it unduly afterwards.

Fascial membranes prepared in this way were always found to be permeable to physiological saline, and at a pressure of $12 \mathrm{~cm}$. water the rate of flow through them was of the order of $60 \mu \mathrm{l}$. per min. This rate was almost immediately increased by some ten times when hyaluronidase (Benger's 'Hylase', 10 units per ml.) was added to the saline perfusate. The same result was obtained with a saline extract of mouse testis.

This effect of hyaluronidase was counteracted by dilute solutions of certain substances of large molecular size. Thus when the following substances, at the $\mathrm{w} / \mathrm{v}$ per cent concentration indicated, were perfused, the original state of permeability was restored within an hour: starch, 0.005 per cent; agar, 0.01 per cent ; gum arabic and citrus pectin, 0.05 per cent; leaf gelatine, 0.1 per cent; chondroitin sulphate and dried serum, $0 \cdot 2$ per cent. Mouse serum at a dilution of $1 / 40$ and human synovial fluid at 1/100 were similarly effective.

In the case of synovial fluid, and to some extent with serum and pectin, the slowing of flow was partly due to viscosity, since it took place rapidly and normal flow was restored almost at once when saline was substituted. But with starch, agar and gum arabic the slowing was gradual, regular and also permanent, inasmuch as no quickening of flow took place when saline was again perfused. 